\title{
Histopathological Effects of Some Essential Oils on Liver and Kidney of Male Albino Mice
}

\author{
Maha W Abou Nazel ${ }^{1}$, Madiha M Talha ${ }^{2 ¥}$, Hoda M Khalifa $^{1}$ \\ ${ }^{1}$ Faculty of Medicine, University of Alexandria, Egypt \\ ${ }^{2}$ Central Agricultural Pesticides Laboratory, Agricultural Research Center, Egypt
}

\begin{abstract}
Background: Plant essential oils play prominent roles as flavoring agents in the food industry and as fragrances for the perfume industry. The World Health Organization has recommended that traditional plants used for the treatment of diseases need further scientific investigation on their toxic side effects. Objectives: The current study was conducted to evaluate the histopathological effect of three plants' essential oils that could be used as insecticides. Methods: Thirty adult male albino mice were divided into five groups. Group I was considered as a control group. Group II, III and IV received cinnamic aldehyde, benzyl alcohol and eugenol essential oils respectively. For comparison with the tested essential oils, Group V received the organophosphorus insecticide dimethoate. Results: Histological examination of liver and renal cortex of animals received the essential oil cinnamic aldehyde or benzyl alcohol revealed a nearly normal histological structure of hepatic parenchyma by Hematoxylin and eosin stain, and normal collagen distribution demonstrated by Gomori's Trichrome stain. Examination of the group IV treated with eugenol revealed few focal areas of degeneration in hepatic parenchyma and in some renal tubules. On the contrary, mice treated with dimethoate manifested severe affection of the hepatic parenchyma with characteristic hepatic zonation and many degenerated cells, pyknotic nuclei and vacuolated cytoplasm in addition to intense cellular infiltration. Thyrodization of the renal cortex of dimethoate treated mice was consistent finding in most of the examined specimens. Many convoluted tubules appeared irregular dilated with flattened epithelial lining. Their lumina were occupied by cellular casts and hyaline material. Thickened basement membranes of the renal tubules with disrupted brush border were also observed. Moreover, extensive fibrosis of hepatic parenchyma and renal interstitium were detected in this group treated with dimethoate. Conclusion: the tested essential oils did not demonstrate significant adverse effects on the liver and renal cortex of albino male mice, while the organophosphorus insecticide, dimethoate, had significant hepatotoxic and nephrotoxic effects. Further studies are needed that include more animals and to address other factors such as gender differences, time course, dose response, blood chemistry, and other biochemical targets prior to any recommendation for the usage of any of these chemicals as insecticides.
\end{abstract}

Available on line at:

https://www.ebscohost.com/academic/arabworld-research-source

$¥$ Correspondence:

Email: Madiha.M.talha@gmail.com

Suggested Citation: Abou Nazel MW, Talha MM, Khalifa HM. Histopathological effects of some essential oils on liver and kidney of male albino mice. Bull high inst Public Health. 2014; 44(2): 88-97.

Keywords: Cinnamic aldehyde, benzyl alcohol, eugenol dimethoate, histopathology liver, kidney

\section{INTRODUCTION}

$\mathrm{P}$ lants have always been an important source of drugs. A large number of the world's populations, especially in developing countries, depend upon medicinal plants as an alternative and complimentary drug therapy for various ailments. Some of the most common practices involve the use of crude plant extracts, which may contain a broad diversity of molecules with often unknown biological effects. $^{(1)}$ Since medicinal plants are used indiscriminately without notifying to their possible unhealthy or toxic effects, the World Health Organization has recommended that traditional plants used for the treatment of diseases need further scientific investigation on their toxic side effects. ${ }^{(2)}$

Traditionally, essential oils have been used for their biological activities, including antiseptic, analgesic, sedative, anti-inflammatory, spasmolytic, and locally anesthetic properties. ${ }^{(3)}$ Furthermore, they 
are used in aromatherapy for health improvement due to their sedative or stimulant properties. ${ }^{(4,5)}$

Plant essential oils are naturally occurring substances often responsible for a plant's distinctive scent or taste. As such, these oils play prominent roles as flavoring agents in the food industry and as fragrances for the perfume industry. ${ }^{(6,7)}$ Generally of rather complex composition, these oils comprise the volatile principles contained in the plants, differentiating them from "fixed oils." There are about 17,500 aromatic compounds that occur in higher plants. ${ }^{(7)}$ Essential oils accumulate in all types of vegetative organs such as flowers (bergamot tree and tuberose), leaves (citronella, eucalyptus), barks (cinnamon), woods (rosewood, sandal wood), roots (vetiver), rhizomes (turmeric, ginger), fruits (allspice, anise, star anise) and seeds (nutmeg). In most cases, the biological function of the essential oils remains obscure. It is conceivable; however, they have an ecological role. For example, many of the plants' essential oil monoterpenoids are found to possess insecticidal activity as well as attractant, repellent, feeding deterrents, ovipositional stimulant activities and change behavior against various insect species. ${ }^{(8-11)}$

The essential oil from Cinnamomum species can be extracted easily by hydro distillation. ${ }^{(12)}$ The oil has been widely used as a flavoring agent and additives for centuries in the food industries.

Monoterpenoids of plant essential oils are neurotoxicants against various insect species. ${ }^{(8)}$ They have been shown to inhibit both gamma-aminobutyric acid (GABA) receptors in marine algi ${ }^{(13)}$, and inhibit acetylcholinesterase (AChE) isolated from different bovine erythrocytes. ${ }^{(14)}$ Previously, the implication of certain G-protein coupled receptors cascade in the mode of action of certain plant essential oil was reported. ${ }^{(8,9,15,16)}$ Based on the usage history of selected plant essential oils, it is speculated that these essential oils provide a good safety profile against mammalian species. For example, cinnamic aldehyde has been used in food industry as flavoring agents, eugenol has been used in fragrance industry, and benzyl alcohol is listed on the USFDA-GRAS (Generally Regarded as Safe) List. Therefore, the current study aimed to address whether these particular plant essential oils induce adverse effects against liver and kidney in laboratory animals.

\section{METHODS}

Experimental animals: The present study was carried using 30 adult male albino mice locally bred at the animal house of the High Institute of Public Health, Alexandria University. The mice were 60-70 days old with body weight ranging between 20-30 grams. Their diet was composed of wheat bread mixed with milk.
Test chemicals: Three essential oils: cinnamic aldehyde, benzyl alcohol and eugenol were used in the current study in the form of 5\% dust supplied by EcoSmart Technologies, Franklin, TN. An organophosphorous insecticide, dimethoate, with 99.5\% purity was used in parallel as a comparison.

Animal treatment: The animals were divided into five groups:

Group I (control): This group included 10 mice; five of them received no treatment. The remaining five were fed the same volume of the carrier as the treated groups. The carrier, talc powder, was freshly mixed with the food every morning for 15 successive days.

Groups II, III, IV: Each of these groups consisted of five mice that received one of the following essential oils: cinnamic aldehyde (group II), Benzyl alcohol (group III), and eugenol (group IV). Animal treatment was initiated by adding $500 \mathrm{ppm}$ of the tested essential oils to the freshly prepared food, including the carrier that was introduced to the animals every morning for 15 successive days. ${ }^{(10)}$

Group V: This group included five mice that received dimethoate in a dose of $10 \mathrm{mg} / \mathrm{Kg}{ }^{(17)}$ to the animal food in the same manner as described above for groups II-IV.

On the sixteenth day, each animal was anaesthetized and sacrificed by decapitation. Subsequently, their liver and kidney were rapidly harvested, dissected and cut into $0.5 \mathrm{~cm}^{3}$ pieces. The cut pieces were further processed into 5-6 $\mu$ paraffin sections and stained with the following using the protocols from Drury and Wilington ${ }^{(18)}$ :

1- Routine H\&E stain to study the structure of the liver and kidney.

2- Gomori's trichrome stain for demonstration of collagen.

3- Periodic Acid Schiff stain for demonstration of basement membranes.

\section{RESULTS}

\section{Liver: $H \& E$ stain}

The parenchyma of control mice liver (group I) showed a classical pattern of branching and anastomosing cords of hepatocytes radiating from the central veins and limiting the sinusoidal spaces lined by endothelial cells and Von Kupffer cells. The hepatocytes appeared polyhedral with granular eosinophilic cytoplasm and rounded central vesicular nuclei with prominent nucleoli. Some of them were binucleated. Portal areas were seen at the angles of the lobules (Fig 1a, b). Examination of the specimens from animals fed cinnamic aldehyde (group II) reflected almost normal control pattern of liver parenchyma (Fig 1c, d). Liver examination of animals fed benzyl alcohol (group III) revealed nearly normal architecture of the hepatic parenchyma in most of the 
examined specimens. Few cells showed vacuolated cytoplasm. A large number of Von Kupffer cells were obviously seen infiltrating the hepatic sinusoids (Fig 1e, f). On the other hand, examination of liver obtained from animals fed eugenol (group IV) revealed focal affection of the hepatic parenchyma.
Some areas appeared with a nearly normal pattern of hepatocytes, other illustrated dilated sinusoidal spaces and scattered foci of hepatocytic disarray. The area of disarray showed hepatocytes with indistinct boundaries and abnormal nuclear pattern (Fig 1g, h).

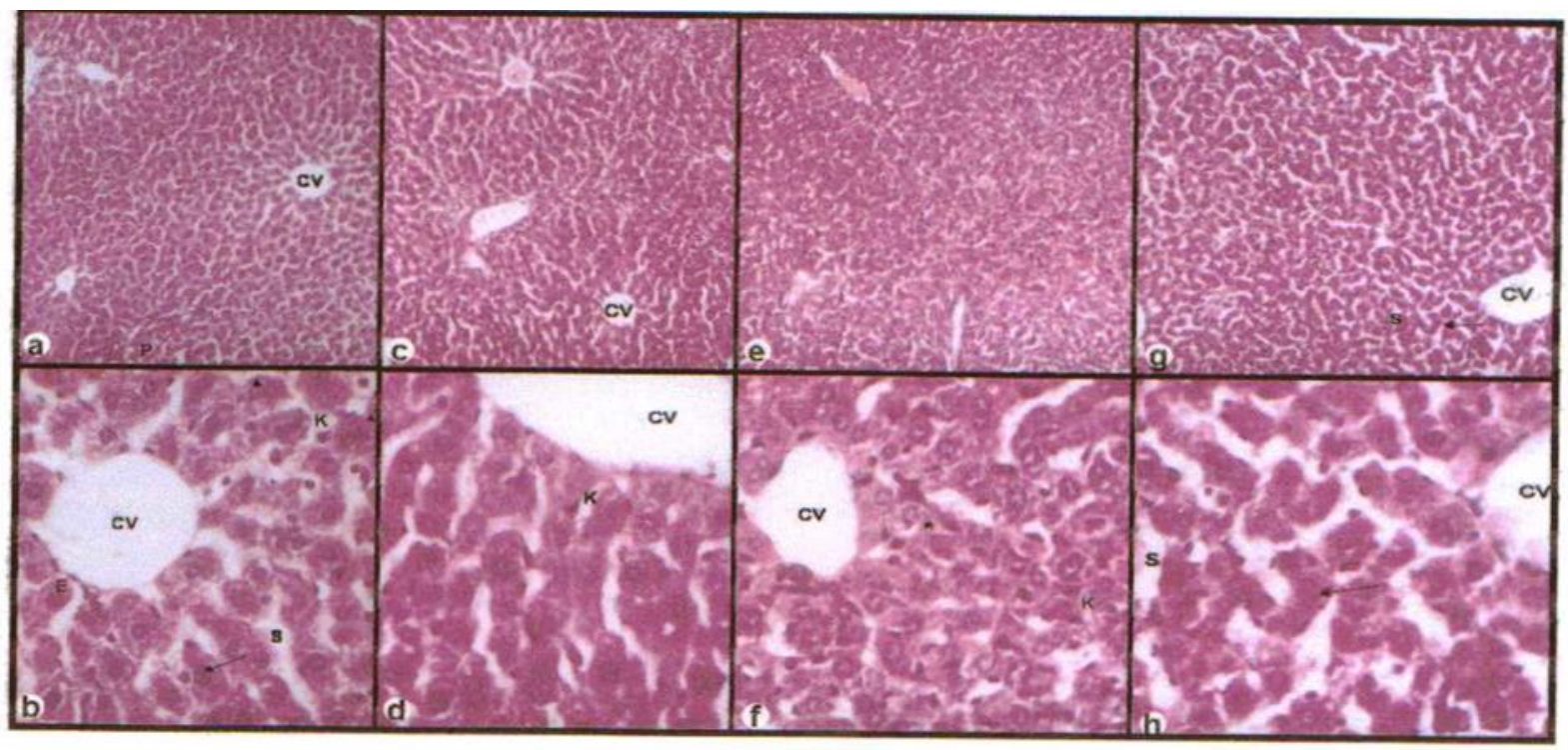

Figure 1 (a-h): H\&E Liver section staining. (a) 100X mag. of control mouse liver section staining with Anastomosing plates of hepatocytes radiating from the central veins indicated by "cv". Portal areas are indicated with "p". (b) $400 \mathrm{X}$ mag. of control mouse liver hepatocytes with eosinophilic cytoplasm and rounded centrally located vesicular nucleus with prominent nucleolus (arrow). Some of them are binucleated (arrow head). S: blood sinusoids; E: endothelial cell; $\mathrm{K}$ : Von Kupffer cell. (c) $100 \mathrm{X}$ mag. of group II liver section stain revealing freely anastomosing plates of nearly normal hepatocytes, limiting the sinusoidal spaces. (d) $400 \mathrm{X}$ mag. of group II liver section stain. (e) $100 \mathrm{X}$ mag. of section stain from group III revealing nearly preserved structure of hepatic lobules. (f) $400 \mathrm{X}$ magnification of section stain from group III showing few cells with vacuolated cytoplasm $\left(^{*}\right)$ and a large number of granular Von Kupffer cells (K). (g) 100X mag. of section stain from group IV treated with eugenol revealing nearly normal array of hepatocytes around central veins (cv). Some areas show dilated sinusoidal spaces (s). Some cells are matted together and with ill defined nuclei (arrows). (h) $400 \mathrm{X}$ mag. of section stain from group IV.

Severe affection of the hepatic parenchyma was manifested in characteristic hepatic zonation of liver specimens collected from animals fed dimethoate (Group V). The periportal areas showed thickened cords of hypereosinophilic cells with glassy homogenous cytoplasm and indistinct boundaries. Their nuclei appeared shrunken with a dense chromatin pattern. The perivenous area showed completely degenerated cells with pyknotic nuclei and vacuolated cytoplasm, surrounded by intense cellular infiltration in the form of neutrophils and lymphocytes together with an increased number of Von Kupffer cells (Fig 2 a,b,c). 


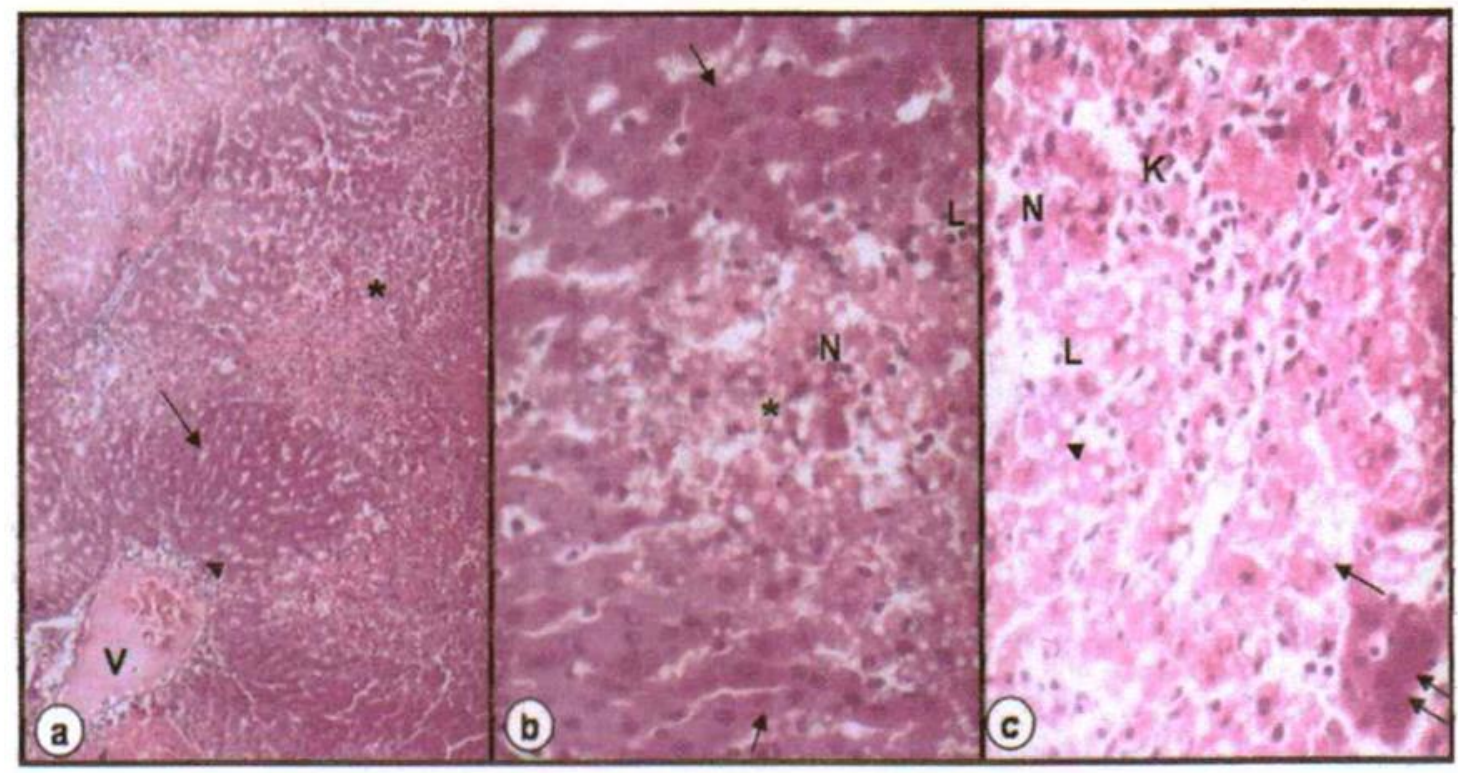

Figure 2(a-c): $\mathrm{H} \& \mathrm{E}$ liver section stain from group $\mathrm{V}$ mouse treated with dimethoate. (a) $100 \mathrm{X}$ mag. of regions of portal area with a congested branch of portal vein (v) surrounded by mononuclear cellular infiltration (arrow head). Note the evident zonation of the hepatocytes; the periportal hepatocytes are highly eosinophilic (arrow), while the perivenous ones are degenerated, shrunken with pyknotic nuclei $(*)$. (b) $400 \mathrm{X}$ mag. of areas of thickened plates of highly eosinophilic hepatocytes (arrows) with glassy homogenous appearance and indistinct cell boundaries. The intervening area $\left({ }^{*}\right)$ shows many hepatocytes with moth-eaten appearance, surrounded by intense cellular infiltration in the form of neutrophils $(\mathrm{N})$ and lymphocytes (L). (c) 400X mag. depicting loss of architecture of hepatocytes which mostly appear swollen with eccentrically located nuclei (arrow) displaced by well circumscribed intra-cytoplasmic vacuoles (arrow head). An area with eosinophilic clumped hepatocytes is also seen (double arrow). Increased number of Von Kupffer cells (K) together with wide spread infiltrate of neutrophils $(\mathrm{N})$ and lymphocytes $(\mathrm{L})$ are also depicted.

\section{Effect of test agents on the distribution of collagen fibers in animal's liver}

To study whether test agents affected the distribution of collagen fibers in livers of fed mice, liver specimens from control animals and animals fed with test agents were stained with Gomori's trichome and examined. Data demonstrated that control livers reflected the normal distribution of collagen fibers around the central veins and portal areas (Fig 3a,b). Examination of groups II and III treated with cinnamic aldehyde and benzyl alcohol, respectively, revealed nearly normal distribution of collagen fibers in the examined sections. Group IV mice liver treated with eugenol illustrated a moderate increase in distribution of collagen fibers in the portal area (Fig 3c). On the other hand, liver specimens of group $\mathrm{V}$ mice, animals fed dimethoate, revealed heavy infiltration of the hepatic parenchyma with collagen fibers as demonstrated around the central veins and portal areas (Fig 3d). 


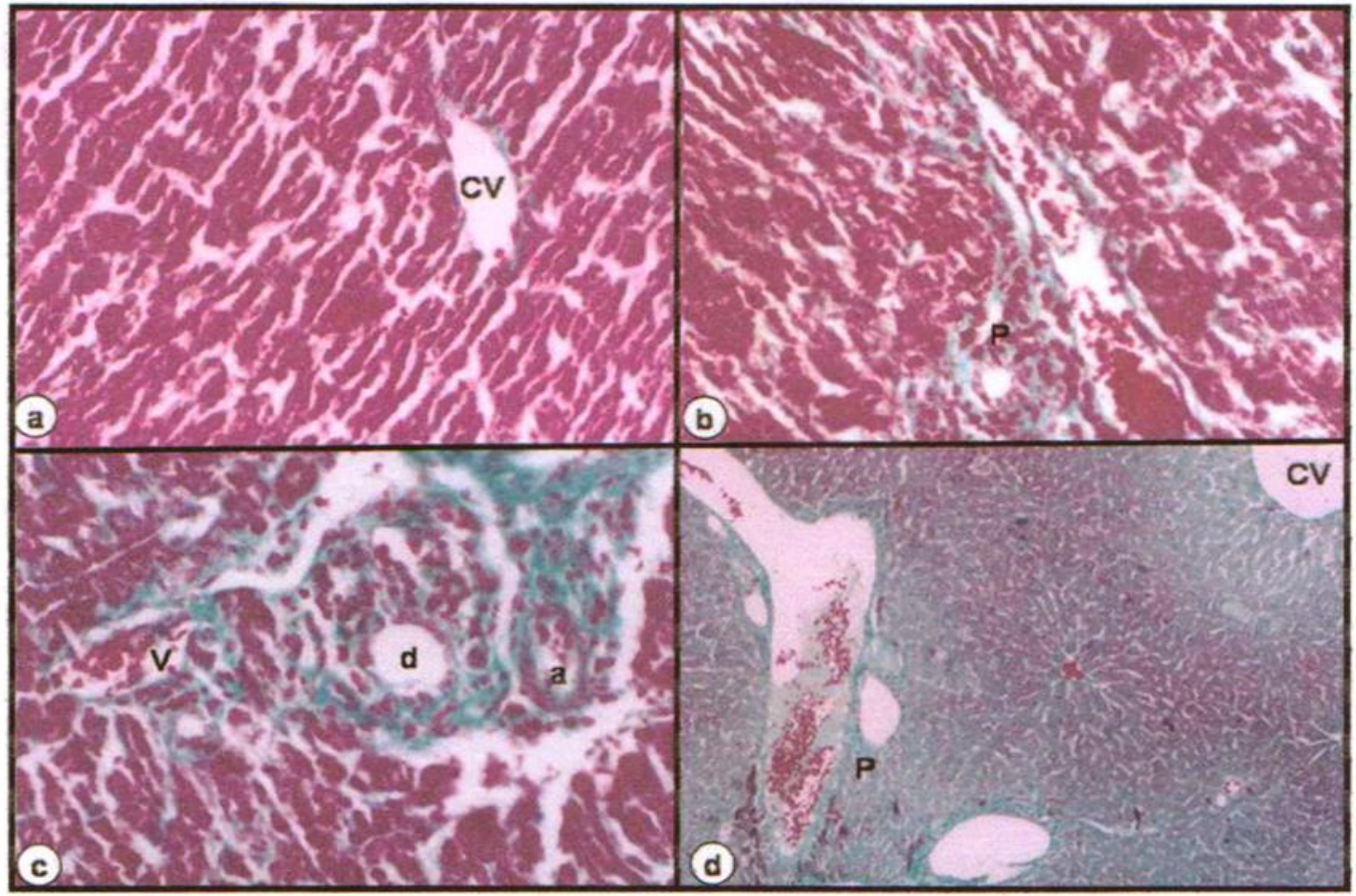

Figure 3(a-d): Gomori's trichrome stain of liver sections. (a) 400X mag. of control mouse liver with normal distribution of collagen fibers around the central veins (cv). (b) $400 \mathrm{X}$ mag. of control mouse liver with normal distribution of collagen fibers around the portal area (p). (c) $400 \mathrm{X}$ mag. of liver section from group IV mouse treated with eugenol revealing moderate increase in deposition of collagen fibers around the branches of hepatic artery (a), portal vein (v) and bile duct (d). (d) $100 \mathrm{X}$ mag. of liver section of group $\mathrm{V}$ mouse treated with dimethoate illustrating heavy deposition of collagen fibers around the portal area (p) and central vein (cv).

\section{Kidney: $H \& E$ stain}

Examination of kidney collected from control mice revealed classical structure and architecture of cortical tissue with well-defined renal corpuscles, proximal and distal convoluted tubules (Fig 4a, b). No histopathological changes were found in animals fed cinnamic aldehyde (group II) as demonstrated by nearly control image (Fig 4c). However, mild peritubular and pericorpuscular cellular infiltration was seen in-group III (Fig 4d; treated with benzyl alcohol). In addition, few renal tubules showed degenerated cells. Furthermore, examination of kidney from group IV treated with eugenol (Fig 4e) revealed focal affection of the renal tubules. Some of them appeared swollen vacuolated while others appeared flattened. Most of the affected tubules had pyknotic nuclei. Intraluminal cellular debris and extruded cells were seen in the degenerated tubules. Moreover, some renal corpuscles showed widened capsular spaces. Moderate peritubular cellular infiltration was noticed in the affected areas (Fig 4e). Mice treated with dimethoate (group V) revealed a massive degree of cortical affection. Thyroidization of cortical tissue was manifested. Many convoluted tubules appeared irregular dilated with flattened epithelial lining. Their lumina were occupied by hyaline material. Other convoluted tubules showed various degrees of degeneration ranging from vacuolated cell lining with pyknotic nuclei to complete degeneration with extrusion of their cells in the lumen. Intense peritubular cellular infiltration was evident in all examined samples (Fig 5a-c).

\section{Effect of test agents on the distribution of collagen fibers in animal's kidney}

Examination of control mice renal cortex revealed the normal distribution of fine greenish collagen fibers in the renal interstitium (Fig 6a). As regard collagen distribution, examination of group II, III and IV mice cortices revealed nearly a control pattern. On the contrary, mice renal cortices of group $\mathbf{V}$ reflected extensive fibrosis of renal interstitium with apparent peritubular collagen fibers deposition (Fig 6b,c). 


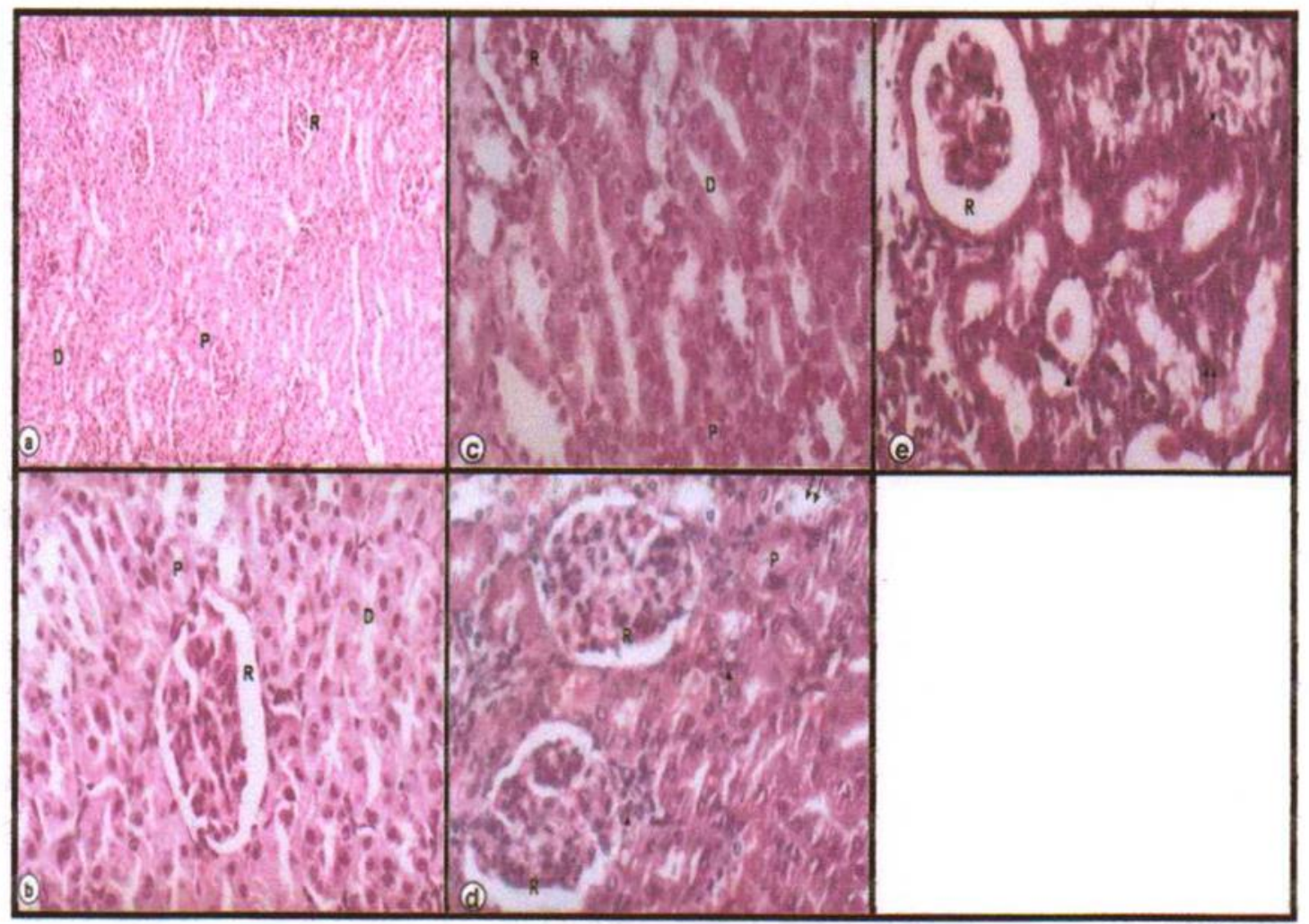

Figure 4(a-e): H\&E stain of kidney sections. (a) 100X mag. of control mouse renal cortex revealing normal structure of cortical tissue with well-defined renal corpuscles (R), proximal (P) and distal (D) convoluted tubules. (b) 400X mag. of control mouse section. (c) $400 \mathrm{X}$ mag of group II section staining that received cinammic aldehyde showing nearly normal structure. R: renal corpuscle, P: Proximal Convoluted Tubule, D: Distal Convoluted Tubule. (d) $400 \mathrm{X}$ mag of renal cortex section of a group III mouse receiving benzyl alcohol show peritubular $(\uparrow)$ and pericorpuscular $(\mathbf{\Delta})$ cellular infiltration. Few tubules show degenerated cells $(\uparrow \uparrow), \mathrm{R}$ : renal corpuscle, P: Proximal Convoluted Tubule. (e) $400 \mathrm{X}$ mag. of renal cortex of group IV that received eugenol revealing variable degrees of tubular affection. Some tubular cells appear swollen vacuolated with pyknotic nuclei and intraluminal extruded cells $(\uparrow)$. Other tubular cells appear flattened with intraluminal cellular debris (A). Renal corpuscle $(\mathrm{R})$ shows widened corpuscular space. Moderate peritubular cellular infiltration (double arrow) is also seen. 


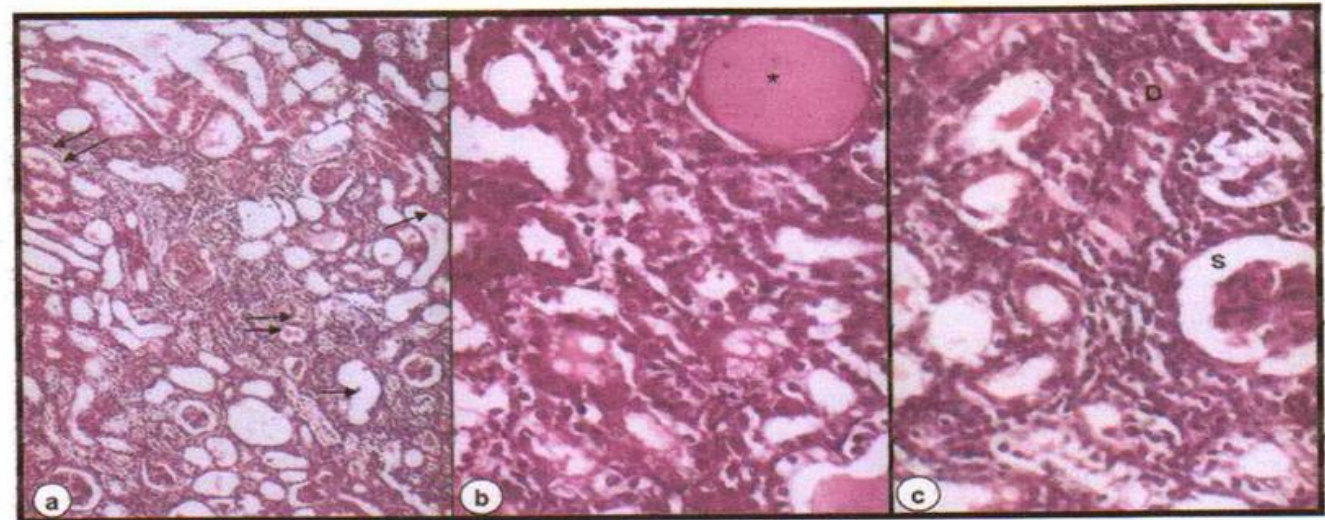

Figure 5(a-c): H\&E stain of renal cortex of a group V mouse treated with dimethoate. (a) $100 \mathrm{X}$ mag. showing thyroidization of the renal cortex. Many convoluted tubules appear irregular, dilated with flattened epithelial lining $(\uparrow)$. Some of them contain intraluminal hyalinized material $(\uparrow \uparrow)$ with intense cellular infiltration $(\wedge)$ in between. (b) $400 \mathrm{X}$ mag. showing severely dilated renal tubule lined by flattened cells and filled with hyalinized material $(*)$. Others are lined by vacuolated swollen cells with pyknotic nuclei ( $\uparrow$ ). (c) $400 \mathrm{X}$ mag. showing severely degenerated tubules with intraluminal extrusion of their lining cells $(\boldsymbol{\Delta})$, intense peritubular mononuclear cellular infiltration $(\uparrow \uparrow)$ and the widened capsular space(S).

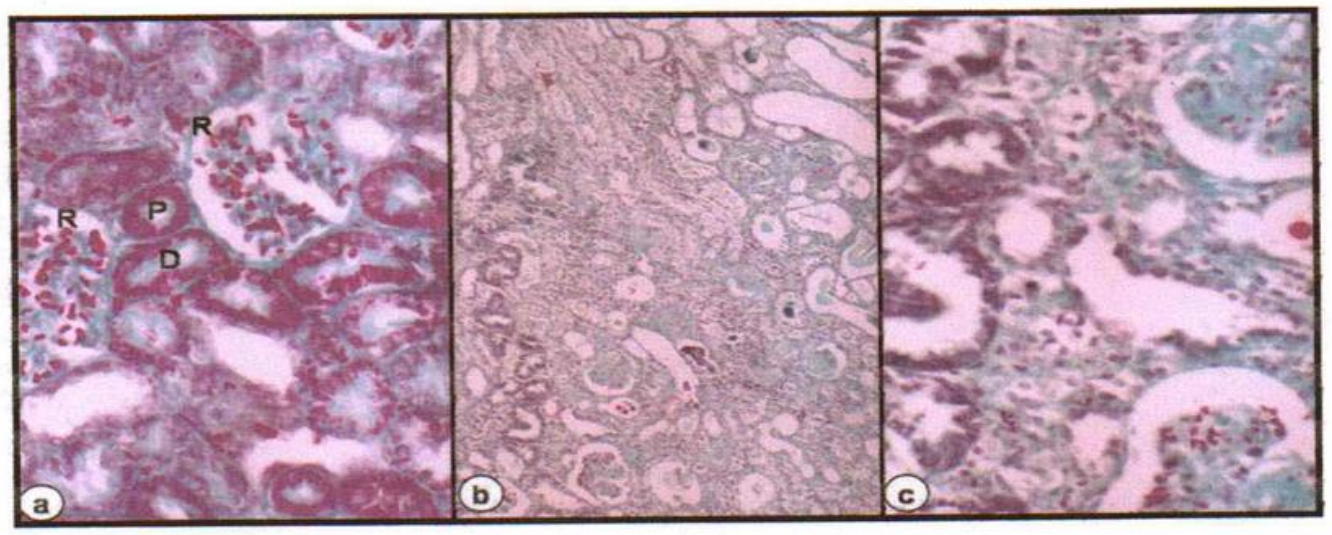

Figure 6(a-c): Gomori's trichrome stain of renal cortex. (a) $400 \mathrm{X}$ mag. of control mouse renal cortex illustrating normal distribution of fine collagen fibers in peritubular and pericorpuscular spaces. R: renal corpuscle, P: proximal convoluted tubule, D: distal convoluted tubule. (b) $100 \mathrm{X}$ mag. of renal cortex section of mouse treated with dimethoate showing extensive fibrosis of renal interstitium. (c) $400 \mathrm{X}$ mag. of renal cortex section of mouse treated with dimethoate showing extensive fibrosis of renal interstitium.

\section{Periodic Acid Schiff stain (PAS)}

Examination of control mice renal cortex revealed positive PAS reaction in the basement membrane and brush border of renal tubules (Fig 7a). Examination of group II, III and IV revealed nearly normal thickness of the basement membrane and intact brush border of the renal tubules as compared with the control group. On the other hand, thickened basement membrane and disrupted brush border were encountered in most of the examined samples of mice renal cortices group V (Fig 7b). 


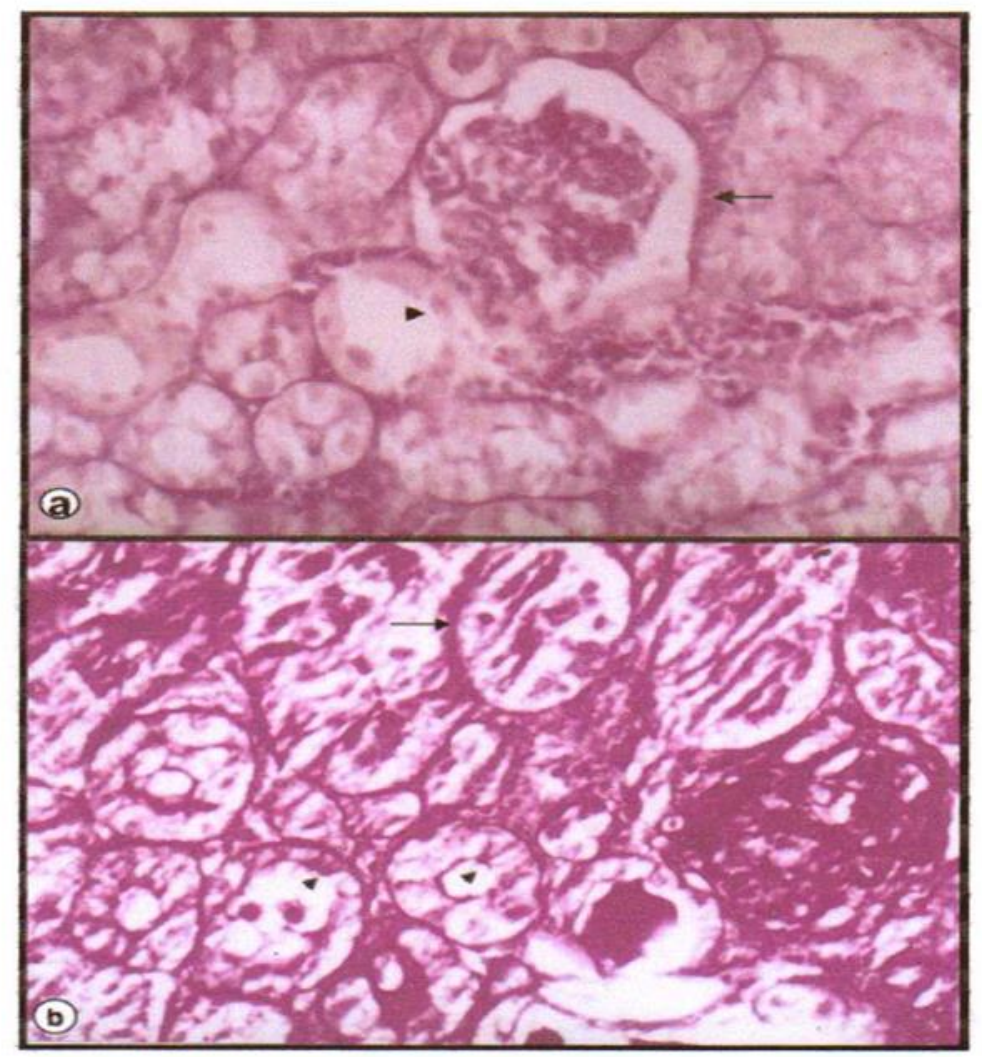

Figure 7(a-b): Periodic Acid Schiff stain of renal cortex sections. (a) $400 \mathrm{X}$ mag. of control mouse renal cortex section with normal thickness of the basement membrane (arrow) and brush border of the renal tubules (arrowhead). (b) $400 \mathrm{X}$ mag. of the renal cortex section of group $\mathrm{V}$ treated with dimethoate revealing thickened basement membrane of renal tubules (arrow) and the disturbed brush border (arrow head).

\section{DISCUSSION}

The examination of liver and kidney of mice received cinnamic aldehyde revealed a nearly normal histological structure. Considering the fact that cinnamic aldehyde demonstrated larvicidal activity against mosquito ${ }^{(19)}$ and insecticidal activity against American cockroaches ${ }^{(20)}$, no histopathological effects of this chemical against laboratory mice were demonstrated by the present data. Gautam and Goel found that the histological studies of liver, spleen, kidney, heart, and testis/ovary did not reveal any pathological changes after treatment even with a higher dose of $800 \mathrm{mg}$ dose of ocimum sanctum extract (OSE) when administered for 28 days. ${ }^{(21)}$ The current findings corroborated with the early report by the National Toxicology Program that showed no evidence of toxicity or carcinogenicity of this essential oil.(22) Furthermore, Xuesen et al. reported that histopathological examination of liver, kidney, colon, lung, heart, spleen, and thymus revealed no signs of Flavokawain A (FKA) induced toxicity after male mice were fed with an AIN-
76A diet or AIN-76A diet supplemented with $0.6 \% \quad$ (6 $\mathrm{g} / \mathrm{kg}$ food) FKA or $0.6 \%$ commercial kava root extract (KRE) for three weeks. ${ }^{(23)}$ On the contrary, Metero et al. ${ }^{(24)}$ proved that high doses of cinnamaldehyde induced genetic alterations at the chromosomal level, and suggested that the liver was the preferential target of its undesirable effects.

Although microscopic examination of livers and kidneys of mice given benzyl alcohol revealed nearly a classical histological structure of the examined specimens which corroborates with the National Toxicology Program (25), the present study demonstrated increased number of Von Kupffer cells in livers as well as peritubular and pericorpuscular mononuclear cellular infiltration in kidneys. Previously, it was suggested that benzyl alcohol treatment might increase prostaglandin synthesis, which is a critical factor in inflammation, apoptosis, and cell growth processes. ${ }^{(26)}$

There are several contradicting reports with regards to the impact of eugenol on human and animal health. For example, the current study did not demonstrate any remarkable histopathological effects of eugenol on liver and kidney structure, except mild degenerative changes 
that were occasionally encountered upon examination of livers and kidneys of treated mice. However, eugenolderivatives such as methyleugenol and isoeugenol were reported to be hepatotoxic, nephrotoxic and carcinogenic ${ }^{(27)}$. In addition, Shakir Ali et al. suggested that eugenolrich fraction (ERF) inhibited the progression of liver fibrosis and development of cirrhosis by ameliorating oxidative stress and inhibiting inflammation, as demonstrated by leukocyte migration. ${ }^{(28)}$ Also Sarikaya reported that eugenol has a promising effect on liver histology in cholestatic liver disease ${ }^{(29)}$. Also worth mentioning a case of liver failure of a 15-month old child after intake of $10 \mathrm{ml}$ clove oil which contains eugenol, isoeugenol and methyleugenol was reported by Janes el al., ${ }^{(30)}$ In addition, Mizutani et al., (31) suggested that a vinylogous quinone methide formed by metabolic oxidation of eugenol might play a role in inducing hepatotoxicity. Usta et al., ${ }^{(32)}$ proposed that the mitochondria is the target for the action of eugenol resulting in derangement of mitochondrial functions, particularly at proton transferring sites. On the other hand, some studies suggested a protective role of eugenol against chemical-induced hepatotoxicity. Krishnaswamy \& Raghuramulu ${ }^{(33)}$, described eugenol as a hepato-protective agent against carbon tetrachloride induced toxicity. This protective role is mediated through inhibition of liver microsomal monooxygenase activities and antiperoxidative activity of eugenol in addition to its role in decreasing $\mathrm{O}_{2}$ formation. ( ${ }^{(34)}$ In addition, Hong et al., (35) concluded that pretreatment with eugenol provided complete protection against the agricultural fungicide $\mathrm{N}-(3$, 5-dichlorophenyl) succinimide nephrotoxicity in rats.

Mice treated with dimethoate revealed massive hepatic and renal degeneration, cellular infiltration and fibrosis. Similarly, Kwape et al. found that lipid peroxidation induced by dimethoate has caused a significant change in liver histological features like widened sinusoids and reduced number of hepatocytes, necrosis and tissue degeneration. ${ }^{(36)}$

John et al., ${ }^{(37)}$ concluded that dimethoate intoxication has been shown to produce oxidative stress. The basis of dimethoate toxicity as an organophosphorous insecticide in the production of reactive oxygen species (ROS) is due to two main mechanisms. The first is its "redox-cycling" activity as it easily accepts an electron to form free radicals and then transfers them to oxygen generating super oxide anions and thence hydrogen peroxide through dismutation reaction. The second mechanism is through generation of free radicals potentially due to the alteration in the normal homeostasis of the body resulting in oxidative stress, provided the requirement of continuous anti-oxidants is not maintained. Due to an induction, the efforts of the endogenous antioxidant enzymes to remove the continuously generated free radicals initially increased, but after later enzyme depletion, resulting in oxidative cell damage occurs. Typically, when the generation of reactive free radicals overwhelms the antioxidant defense, lipid peroxidation of the cell membrane occurs. Lipid peroxidation causes disturbance in cell integrity leading to cell damage/death.$^{(38,39)}$ This was recently further proven by Sharma et al., ${ }^{(40)}$ who indicated an increase in hepatic cytochrome $\mathrm{P} 450$, lipid peroxidation, catalase, superoxide dismutase, glutathione peroxidase and glutathione reductase in liver and brain in dimethoate-intoxicated rats.

The thyroidization of renal cortices with increased incidence of hyaline droplets and granular casts that was observed in the renal tubules of dimethoate-intoxicated mice was previously described as one of the microscopic features of end-stage renal disease. Cigremis et al., ${ }^{(41)}$ correlated similar histological feature with the oxidative burst in rat kidney by increasing the formation of reactive oxygen species and elevation of reduced glutathione (GSH) and malondialdehyde (MDA) levels. Moreover, Yamazaki et al., ${ }^{(42)}$ attributed it as an example of alpha $2 \mathrm{v}-$ globulin nephropathy. Kaur and Dhanju ${ }^{(43)}$ also reported that dimethoate induced cellular toxicity even after its subchronic administration in low doses for a long period.

The observed excessive hepatic and renal fibrosis in the dimethoate group of the current study corroborated with the work of Reddy et al., ${ }^{(44)}$ who reported that the rates of catabolism of both soluble and insoluble collagens were decreased in higher doses of dimethoate with impairment of crosslinking and maturation of collagen. Moreover, the observed hepatic and renal cellular infiltration in the current work corroborated with the results of Kaur and Dhanju ${ }^{(43)}$ that proved dimethoate toxicity was associated with cellular infiltration.

In conclusion, the tested essential oils did not demonstrate significant adverse effects on the liver and renal cortex of albino male mice, while the organophosphorus insecticide, dimethoate, had significant hepatotoxic and nephrotoxic effects. Further studies are needed that include more animals and to address other factors such as gender differences, time course, dose response, blood chemistry, and other biochemical targets prior to any recommendation for the usage of any of these chemicals as insecticides.

\section{ACKNOWLEDGEMENTS}

This work was supported by Essam Enan (Vanderbit University School of Medicine- Department of biochemistry) and Nadia Abou El Ela (High Institute of Public Health)

\section{REFERENCES}

1. Yakob HK, Uyub AM, Sulaiman SF. Toxicological evaluation of 80\% methanol extract of Ludwigia octovalvis (Jacq.) P.H. Raven leaves (Onagraceae) in BALB/cmice. Journal of Ethnopharmacology. 2012;142:663-8.

2. World Health Organization. Guidelines on Safety Monitoring of Herbal Medicines in Pharmacovigilance Systems. Geneva: WHO; 2008.

3. Bakkali F, Averbeck S, Averbeck D, Idaomar M. Biological effects of essential oils - a review. Food and Chemical Toxicology. 2008;46(2):446-75. 
4. Edris AE. Pharmaceutical and therapeutic potentials of essential oils and their individual volatile constituents: a review. Phytotherapy Research. 2007;21(4):308-23.

5. Yim VWC, Ng AKY, Tsang HWH, Leung AY. A review on the effects of aromatherapy for patients with depressive symptoms, The Journal of Alternative and Complementary Medicine. 2009; 15(2): $187-95$.

6. Templeton W. An introduction to the chemistry of terpenoids and steroids. London; Butter worth and Co. Ltd. 1969: 1-70.

7. Bruneton J. Pharmacogoncy, phytochemistry, Medicinal Plants: Essential oils $2^{\text {nd }}$ ed. New York: Lavoisier Publishing. 1999: 461780.

8. Enan E. Insecticidal action of terpenes and phenols to the cockroaches: effect on octopamine receptors. International symposium on crop protection. Gent, Belgium. May 1998.

9. Enan EE. Insecticidal activity of essential oils: Octopaminergic sites of action. Comp Biochem Physiol. Part C; 2001;130(3):325- 37.

10. Abou El-Ela NE, Enan EE. Insecticidal activity of some essential oils: cAMP mediates effect. Bull High Inst Public Health. 2002; 3(1): 15- 30.

11. Sawamura M, Sun SH, Ozaki K, Ishikawa J, Ukeda H. Inhibitory effects of citrus essential oils and their components on the formation of N-nitrosodimethylamine. J Agri Food Chem 1999; 47: 4868- 72.

12. Singh G, Maurya S, De Lampasona MP, Catalan CAN: A comparison of chemical, antioxidant and antimicrobial studies of cinnamon leaf and bark volatile oils, oleoresins and their constituents. Food Chem Toxicol. 2007;45:1650-61.

13. Coats JR. Mechanisms of toxic action and structure-activity relationships for organochloride and synthetic pyrethroid insecticides. Environ Health Prespect 1990; 87: 255- 62.

14. Miyazawa $\mathrm{M}$, Watanabe $\mathrm{H}$, Kameoka $\mathrm{H}$. Inhibition of acetylcholinesterase activity by monoterpenoids with a p-menthane skeleton. J Agric Food Chem. 1997; 45: 677- 9.

15. Bischof LJ, Enan EE. Cloning, expression and functional analysis of an octopamine receptor from Periplaneta americana. Insect Biochem Mol Biol. 2004; 34: 511- 21.

16. Enan EE. Molocular response of Drosophila melanogaster tyramine receptor cascade to plant essential oils. Insect Biochem Mol. 2005;35:309-21.

17. Farag AT, El-Aswad AF, Shaaban NA. Assessment of reproductive toxicity of orally administered technical dimethoate in male mice. Reprod Toxicol. 2007;23(2):232-8.

18. Drury RB, Wilington EA. Histological techniques $5^{\text {th }}$ ed. 2009 . Oxford, New York: Oxford University Press; 140- 2, 185- 6, 248 - 9.

19. Cheng SS, Liu JY, Tsai KH, Chen WJ, Chang ST. Chemical composition and mosquito larvicidal activity of essential oils from leaves of different Cinnamomum osmophloeum provenances. J Agric Food Chem. 2004;52(14):4395-400.

20. Enan E. Insecticidal activity of essential oils: octopaminergic sites of action. Comp. Biochem. Physiol. Part C 130. Toxicol Pharmacol. 2001:3:325- 37.

21. Gautam MK, Goel RK. Toxicological Study of Ocimum sanctum Linn Leaves:Hematological, Biochemical, and Histopathological Studies. Journal of Toxicology; 2014; Article ID 135654, 9 pages.

22. National Toxicology Program (NTP) toxicology and carcinogenesis studies of trans-cinnamaldehyde (CAS No. 14371-10-9) in F344/N rats and $\mathrm{B} 6 \mathrm{C} 3 \mathrm{~F} 1$ mice (Feed Studies). Food Chem Toxicol. 2002;40(7):935-40.

23. Xuesen Li, Xia Xu, Tao Ji, Zhongbo Liu, Mai Gu, Bang H. Hoang, and Xiaolin Zi.. Dietary feeding of Flavokawain A, a Kava chalcone, exhibits a satisfactory safety profile and its association with enhancement of phase II enzymes in mice. Toxicol Rep. 2014; 1: 211.

24. Mereto E, Brambilla-Campart G, Ghia M, Martelli A, Brambilla G. Cinnamaldehyde-induced micronuclei in rodent liver. Mutat Res. 1994;322(1):1-8.

25. National Toxicology Program (NTP) Toxicology and Carcinogenesis Studies of Benzyl Alcohol (CAS No. 100-51-6) in F344/N Rats and B6C3F1 Mice (Gavage Studies). Natl Toxicol Program Tech Rep Ser. 1989;343:1-158.
26. Martinez B, Perez-Castillo A, Santos A. The mitochondrial respiratory complex I is a target for 15-deoxy-delta12, 14prostaglandin J2 action. J Lipid Res. 2005;46(4):736- 43.

27. Catherine JP, Melissa CM, Christina B. NTP Toxicology and carncinogenesis Nationa Toxicology Program. Studies of methyleugenol (CAS NO. 93-15-2) in F344/N Rats and B6C3F1 Mice (Gavage Studies). Natl Toxicol Program Tech Rep Ser. 2000;491:1-412.

28. Ali S, Prasad R, Mahmood A, Routray I, Salihu T, Sahin K, Kucuk O. Eugenol-rich Fraction of Syzygium aromaticum (Clove) Reverses Biochemical and Histopathological Changes in Liver Cirrhosis and Inhibits Hepatic Cell Proliferation. Journal of cancer prevention. 19(4): December, 2014

29. Sarikaya M, Filik L, Ergul B, Dogan Z, Alparslan Gonultas M, Hucumenoglu S, Can M, Duymus ME. Favourable effect of Eugenol on liver histology in acute cholestasis in rats after bile duct ligation. Bratisl Lek Listy. 2014;115(10):622-4.

30. Janes SE, Price CS, Thomas D. Essential oil poisoning: Nacetylcysteine for eugenol-induced hepatic failure and analysis of a national database. Eur J Pediatr. 2005;164(8):520- 2.

31. Mizutani T, Satoh K, Nomu H. Hepatotoxicity of eugenol and related compounds in mice depleted of glutathione: structural requirements for toxic potency. Res Commun Chem Pathol Pharmacol. 1991;73(1):87-95.

32. Usta J, Kreydiyyeh S, Bajakian K, Nakkash-Chmaisse H. In vitro effect of eugenol and cinnamaldehyde on membrane potential and respiratory chain complexes in isolated rat liver mitochondria. Food Chem Toxicol. 2002;40(7):935- 40.

33. Krishnaswamy K, Raghuramulu N. Bioactive phytochemicals with emphasis on dietary practices. Indian J Med Res. 1998; 108: 167- 81.

34. Chericoni S, Prieto JM, Iacopini P, Cioni P, Morelli I. In vitro activity of the essential oil of Cinnamomum zeylanicum and eugenol in peroxynitrite-induced oxidative processes. J Agric Food Chem. 2005;53(12):4762-5.

35. Hong SK, Anestis DK, Brown PI, Rankin GO. Effect of glucuronidation substrates/inhibitors on N-(3, 5-dichlorophenyl) succinimide nephrotoxicity in Fischer 344 rats. Toxicology; 1999;132(1):43-55.

36. Kwape TE, ChaturvedI PJM, Amau K, George S. Hepato protective potential of methanol extract of leaf of ziziphus mucronata (zmlm) against dimethoate toxicity: biochemical and histological approach. Ghana medical journal; 2013;47(3):112-20.

37. John S, Kale M, Rathore N, Bhatnagar D. Protective effect of vitamin $\mathrm{E}$ in dimethoate and malathion induced oxidative stress in rat erythrocytes. J Nutr Biochem. 2001; 12(9): 500- 4.

38. Sharma Y, Bashir S, Irshad M, Nag TC, Dogra TD. Dimethoateinduced effects on antioxidant status of liver and brain of rats following subchronic exposure. Toxicology; 2005; 215(3): 173- 81.

39. Vidyasagar J, Karunakar N, Reddy MS, Rajnarayana K, Surender T, Krishna DR. Oxidative stress and antioxidant status in acute organophosphorous insecticide poisoning. Ind $\mathrm{J}$ Pharm. 2004;36(2):76-9.

40. Sharma Y, Bashir S, Irshad M, Gupta SD, Dogra TD. Effects of acute dimethoate administration on antioxidant status of liver and brain of experimental rats. Toxicology. 2005;206(1):49-57.

41. Cigremis Y, Turkoz Y, Akgoz M, Sozmen M. The effects of chronic exposure to ethanol and cigarette smoke on the level of reduced glutathione and malondialdehyde in rat kidney. Urol Res. 2004; 32(3): 213-8.

42. Yamazaki K, Aiso S, Matsumoto M, Arito H, Nagano K, Yamamoto S, Matsushima T. Thirteen-week oral toxicity study of 1,4-dichloro2-nitrobenzene in rats and mice. Ind Health. 2005; 43(3):597-610.

43. Kaur S, Dhanju CK. Enzymatic changes induced by some organophosphorus pesticides in female rats. Indian J Exp Biol. 2004;42(10):1017-9.

44. Reddy PN, Durai Raj GD, Dhar SC. Toxic effect of dimethoate on the crosslinking of gingival and uteral collagen in female albino rats fed with normal and high protein diets. Biochem Int. 1991;23(6):1117- 26. 